\title{
Baseline Iron Status and Indices of Oxidative Stress in a Cohort of Pregnant Women in Kinshasa, DR Congo
}

\author{
Andy Muela Mbangama, Tandu-Umba Barthélémy, Mbungu Mwimba Roger \\ Department of Obstetrics and Gynecology, University Clinics of Kinshasa, Kinshasa, DR Congo \\ Email: dymuela@yahoo.fr
}

How to cite this paper: Mbangama, A.M., Barthélémy, T.-U. and Roger, M.M. (2018) Baseline Iron Status and Indices of Oxidative Stress in a Cohort of Pregnant Women in Kinshasa, DR Congo. Open Journal of Obstetrics and Gynecology, 8, 1476-1486. https://doi.org/10.4236/ojog.2018.814149

Received: October 26, 2018

Accepted: December 3, 2018

Published: December 7, 2018

Copyright ( 92018 by authors and Scientific Research Publishing Inc. This work is licensed under the Creative Commons Attribution International License (CC BY 4.0).

http://creativecommons.org/licenses/by/4.0/

\begin{abstract}
Objective: To determine baseline iron and oxidative status in a cohort of pregnant women before iron supplementation in our setting. Background: Screening of iron deficiency before supplementation during pregnancy has been scarce. Therefore, following routine iron supplementation confounding results might be found in outcomes of groups of patients considered. Taking in account that body/serum iron status is reportedly linked to maternal oxidative status, we aimed to associate assessment of baseline iron and oxidative status of women in need of oral supplementation during pregnancy. Methods: This is a cross-sectional study concerning 74 women attending antenatal care at the University Clinics of Kinshasa from September 2017 throughout June 2018, with a singleton pregnancy not exceeding 19 weeks, regardless of age and parity. Variables of the study included sociodemographic and anthropometric ones along with parameters of iron status (hemoglobin, hematocrit, ferritin, serum iron, transferrin and iron saturation capacity). Oxidative status was assessed using superoxide dismutase (SOD) and uric acid as antioxidants, while oxidant agents were oxidized LDL and blood glucose (beside serum iron and ferritin). According to local standards anemia was defined as hemoglobin $<10 \mathrm{~g} / \mathrm{L}$ and pathologic serum ferritin as $<15 \mathrm{ng} / \mathrm{ml}$. For statistical calculations we used t-test, chi-square test and Pearson's correlation test, the significance being stated at $\mathrm{p} \leq 0.05$. Results: At recruitment (15.9 \pm 1.79 week gestational age) mean hemoglobin value of the overall study group was $10.3 \pm 1.5 \mathrm{~g} / \mathrm{dl}$. Anemia was diagnosed to 39 women that represented $52.2 \%$ of the study group, most of anemic women belonging to low socioeconomic sub-group $(69.2 \%$ vs $29 \%$; $\mathrm{P}<0.001)$. The majority was para 2 , with average weight of $70.2 \pm 14.5 \mathrm{Kg}$ (P not significant between sub-groups) and BMI of $26 \pm 5.2 \mathrm{Kg} / \mathrm{m}^{2}(\mathrm{P}<0.01)$. The proportion of obeses was $18.9 \%$. The proportion of intestinal parasitosis was significantly
\end{abstract}


higher among anemic women $(61.5 \%$ vs $34.3 \%$; $\mathrm{P}<0.02)$ that had lower alimentary iron intake $(22.8 \pm 4.9 \mathrm{gr} /$ day vs $31.4 \pm 9.5 \mathrm{gr} ; \mathrm{P}<0.001)$. Of markers of iron status serum ferritin and iron were lower in anemic women $(7.5 \pm 3.9$ $\mathrm{ng} / \mathrm{ml}$ vs $35.7 \pm 17.1 \mathrm{ng} / \mathrm{ml} ; \mathrm{P}<0.001$ and $52.7 \pm 38.9 \mu \mathrm{g} / \mathrm{dl}$ vs $96.2 \pm 41.8$ $\mu \mathrm{g} / \mathrm{dl}$, respectively. Both sub-groups were similar in serum transferrin. As of markers of oxidative stress anemic women had significantly higher superoxide dismutases (SOD) $(1056.4 \pm 762.1 \mathrm{UI} / \mathrm{L}$ vs $682.6 \pm 543.9 \mathrm{UI} / \mathrm{L}(\mathrm{P}<0.02)$ and oxidizedd anti LDL Ac $(439.6 \pm 209.5 \mathrm{UI} / \mathrm{L}$ vs $192.8 \pm 136.3 \mathrm{UI} / \mathrm{L}(\mathrm{P}<$ 0.001 ). Serum iron, ferritin, SOD and oxidized LDL were more likely to assess iron and oxidative status in our setting. Conclusion: The rate of anemic mothers found in our study (52.2\%) has been quite constant in our setting for years, meaning endemicity. Serum iron and ferritin were significantly lower in anemic women, which is supportive of routine iron supplementation during pregnancy. Significantly higher level of SOD and oxidized LDL in anemic women suggests that maternal anemia may count into oxidative stress likely to be found in these women.

\section{Keywords}

Iron Status, Oxidative Stress, Pregnant Women, Kinshasa

\section{Introduction}

It is worldwide admitted that maternal anemia induces a heavy morbidity that affects both mother and infant through a great variety of tissue hypoxia-related symptoms for mother and pre-term delivery and low birth weight for infant [1].

In order to reduce this maternal and perinatal morbidity/mortality World Health Organization adopted cost-effective preventive interventions during pregnancy including iron-folic acid supplementation, de-hookworming medication and anti-malarial prevention or treatment [1] [2].

It is postulated that the most prevalent type of anemia during pregnancy is iron-deficient one, which makes iron administration the central part of the prevention. Due to the fact that ferrous iron salts are absorbed three times faster than ferric they should be prefered in this form [3].

Placenta contains transitional metals such as iron. This makes it produce free radicals that represent basis for enhancement of both oxidative and antioxidative phenomena during pregnancy [4] [5] [6]. Additionally, blood/body iron deficiency during pregnancy has been claimed causative of increase in oxidants and decrease in antioxidants, likely to induce oxidative stress. When supplementation is planned, however, one should consider that ingested iron, either well absorbed (only $3 \%-5 \%$ ) or remaining (in a great amount) in intestinal canal, represents a potent pro-oxidant agent. It could thus precipitate an oxidative stress. So, following routine iron administration, confounding results are to be expected in pregnancy outcomes traditionally solely attributed to anemic condition. Therefore, assessment of such results gains to be based on knowledge of 
baseline iron of women concerned.

However, due to poverty in developing countries screening of iron deficiency before supplementation has been scarce as it can be noted through numerous papers addressing frequencies of maternal anemia and its causative factors that seem to be similar in all settings: low socioeconomic environment, insufficient nutritional iron intake and bad hygienic conditions favoring infestation with parasitoses [7]-[17]. As of assessment of oxidative status during pregnancy, it still represents a luxury.

In Algeria, Imene [12] reported oxidative status in 10 obese pregnant women as compared with 10 diabetic, 10 diabetic with hypertension and 10 controls without mention of iron status. He found that obese mothers and their newborns had increased lipid and protein peroxidation, low levels of glutathione and high methemoglobin compared with control mothers. He concluded that oxidative stress was an important risk factor for aggravating metabolic abnormalities in obese women. So, data related to both iron and oxidative status during pregnancy in Africa do not exist.

In the present study, we took in account that body/serum iron status is reportedly linked to maternal oxidative stress [4]. So, we aimed to associate assessment of baseline iron and oxidative status of pregnant women supposed in need of oral supplementation.

\section{Methods}

This is a cross-sectional study concerning women belonging to a prospective cohort followed at the University Clinics of Kinshasa during 10 months (September 2017 throughout June 2018), the protocol of which was recently published [3]. The study sample was represented by pregnant women with a singleton pregnancy not exceeding 19 weeks (starting point of iron supplementation), without obvious pathology likely to have a negative influence on pregnancy (hypertension, diabetes mellitus, sickle cell disease, HIV, malaria, respiratory insufficiency) and regardless of age and parity. This study was conducted according to Helsinky recommendations. Eligible women were definitely recruited after informed and written consent to participate in the study.

The sampling was carried out consecutively for all pregnant women presenting themselves at prenatal care until completion of 74 women (the minimum size of 54 as calculated according to appropriate formulas +20 women for potential drop out).

\section{Variables of the study and subjects monitoring}

1) Sociodemographic and anthropometric variables: age, marital status, parity, weight, height, number and abortion type, education level, economic status, body mass index (BMI) calculated from weight and height.

2) Alimentary iron intake according to 24 -hour recall method.

3) Intestinal parasitic infection (through direct microscopic examination of the stools), a medical condition known to limit iron absorption. 
4) Biological parameters of iron status included hemoglobin, hematocrit, ferritin, serum iron, transferrin and iron saturation capacity. Oxidative status was assessed using superoxide dismutase or SOD and uric acid as antioxidants, while oxidant agents were oxidized LDL and blood glucose (beside serum iron and ferritin).

Hemoglobin and hematocrit were measured using a KX-21N automated hematology analyzer. According to local standards anemia was defined as hemoglobin $<10 \mathrm{~g} / \mathrm{L}$ and pathologic serum iron and ferritin as $<15 \mu \mathrm{g} / \mathrm{L}$ and $34 \mathrm{ng} / \mathrm{ml}$, respectively.

Serum iron $(\mathrm{Fe})$ and saturation of transferrin (\% sat) were measured with a manual spectrophotometrical assay (kit 565-A, Sigma St. Louis Mo). Ferritin was analyzed by the chemiluminescence method (on the Immulite analyzer, Diagnostic Products Corporation). Uric acid and fasting blood glucose were assessed with a manual spectrophotometrical assay (kit Spectrum 722, 18TS1505007). SOD was measured with a manual spectrophotometrical assay (kit Biolabo Diagnostic's, Kenza Max Biochemistry serial n³4840). Oxidized LDL was analyzed by the ELISA method (on the Elisa analyzer, Humareader signe plus 1800). Direct examination of stool was done with binocular microscope Olympus XSZ-107BN.

\section{Statistical calculations}

Data were entered using Microsoft Excel 2007 software and exported to SPSS 21.0 for analysis. For normally distributed parametric data, comparisons of averages were made using t-test and comparisons of proportions with chi-square test.

Pearson's correlation test between biologic markers was used to seek potential associations with oxidative stress. Testing was stated significant at $\mathrm{p} \leq 0.05$.

This study has been designed and financed by our own funds.

\section{Ethical Considerations}

This project was prepared according to the Declaration of Helsinki and was agreed by Ethics Committee of Public Health School of University of Kinshasa.

\section{Results}

Of 372 women attending antenatal care at the university clinics during the study period 74 filled the enrollment criteria. At recruitment (15.9 \pm 1.7 weeks of gestational age) mean hemoglobin value of the overall study group was $10.3 \pm 1.5$ $\mathrm{g} / \mathrm{dl}$. Anemia was diagnosed to 39 women that represented $52.2 \%$ of the study group, most of them belonging to low socioeconomic sub-group $(69.2 \%$ vs $29 \%$; $\mathrm{P}<0.001)$. Table 1 shows that the majority was para 2 , with average weight of $70.2 \pm 14.5 \mathrm{Kg}$ ( $\mathrm{P}$ not significant between sub-groups) and BMI of $26 \pm 5.2$ $\mathrm{Kg} / \mathrm{m}^{2}(\mathrm{P}<0.01)$. The proportion of obeses was $18.9 \%$.

The proportion of intestinal parasitosis was significantly higher among anemic women $(61.5 \%$ vs $34.3 \%$; $\mathrm{P}<0.02)$ that had significantly lower alimentary iron intake $(22.8 \pm 4.9$ gr vs $31.4 \pm 9.5$ gr; $\mathrm{P}<0.001)$. 
It can be noted in markers of iron status (Table 2) that serum ferritin and iron were significantly lower in anemic women $(7.5 \pm 3.9 \mathrm{ng} / \mathrm{ml}$ vs $35.7 \pm 17.1 \mathrm{ng} / \mathrm{ml}$; $\mathrm{P}<0.001$ and $52.7 \pm 38.9 \mu \mathrm{g} / \mathrm{dl}$ vs $96.2 \pm 41.8 \mu \mathrm{g} / \mathrm{dl} ; \mathrm{P}<0.001$, respectively) Both sub-groups were similar in serum transferrin and coefficient of saturation of transferrin.

Comparing markers of oxidative stress of anemic women with those of women with normal $\mathrm{Hb}$ values (Table 3 ) we found that anemic women had significantly higher superoxide dismutases (SOD) $(1056.4 \pm 762.1 \mathrm{UI} / \mathrm{L}$ vs $682.6 \pm$ 543.9 UI/L; $\mathrm{P}<0.02)$ and oxidized LDL $(439.6 \pm 209.5 \mathrm{UI} / \mathrm{L}$ vs $192.8 \pm 136.3$

Table 1. General characteristics of the study group.

\begin{tabular}{ccccc}
\hline Chacteristics & $\begin{array}{c}\text { Overall } \\
\text { group }\end{array}$ & $\begin{array}{c}\text { Anemic women } \\
(\mathbf{n}=39)\end{array}$ & $\begin{array}{c}\text { Non anemic women } \\
(\mathbf{n}=\mathbf{3 5})\end{array}$ & $\mathrm{p}$ \\
\hline $\begin{array}{c}\text { Sociodemographic } \\
\text { Age (yrs) }\end{array}$ & $32.2 \pm 5.2$ & $32.3 \pm 4.7$ & $32.03 \pm 5.7$ & 0.82 \\
$\begin{array}{c}\text { Alimentary iron intake } \\
\text { (gr per day) }\end{array}$ & $26.9 \pm 8.6$ & $22.8 \pm 4.9$ & $31.4 \pm 9.5$ & $<\mathbf{0 . 0 0 1}$ \\
$\begin{array}{c}\text { Low socioeconomic level (\%) } \\
\text { Clinical }\end{array}$ & 37.8 & 69.2 & 2.9 & $<\mathbf{0 . 0 0 1}$ \\
$\begin{array}{c}\text { Poids (Kg) } \\
\left.\text { BMI (Kg/m }{ }^{2}\right)\end{array}$ & $70.2 \pm 14.5$ & $67.7 \pm 15.9$ & $73.01 \pm 12.2$ & 0.114 \\
Parity & $26 \pm 5.2$ & $27.8 \pm 5.4$ & $24.03 \pm 4.3$ & $<\mathbf{0 . 0 1}$ \\
Gravidity & $2 \pm 1$ & $2 \pm 1$ & $2 \pm 1$ & 0.171 \\
(\%) & $3 \pm 1$ & $3 \pm 1$ & $3 \pm 1$ & 0.247 \\
Presence of intestinal parasitosis & 48.6 & 61.5 & 34.3 & $<\mathbf{0 . 0 2}$ \\
\hline
\end{tabular}

Table 2. Markers of iron status of the study group.

\begin{tabular}{ccccc}
\hline Markers & Overall group & $\begin{array}{c}\text { Anemic women } \\
(\mathbf{n}=39)\end{array}$ & $\begin{array}{c}\text { Non anemic women } \\
(\mathbf{n}=35)\end{array}$ & $\mathrm{p}$ \\
\hline Ferritin $(\mathrm{ng} / \mathrm{ml})$ & $20.9 \pm 18.6$ & $7.5 \pm 3.9$ & $35.7 \pm 17.1$ & $<0.001$ \\
Serum iron $(\mu \mathrm{g} / \mathrm{dl})$ & $73.3 \pm 45.7$ & $52.7 \pm 38.9$ & $96.2 \pm 41.8$ & $<0.001$ \\
Transferrin $(\mathrm{g} / \mathrm{L})$ & $119.5 \pm 72.2$ & $107.2 \pm 45.9$ & $133.1 \pm 91.9$ & 0.125 \\
CST $(\%)$ & $2.6 \pm 1.1$ & $2.5 \pm 1.1$ & $2.8 \pm 1.1$ & 0.357 \\
\hline
\end{tabular}

CST: coefficient of saturation of tansferrin.

Table 3. Markers of oxidative stress of study group.

\begin{tabular}{ccccc}
\hline Markers & Overall group & $\begin{array}{c}\text { Anemic women } \\
(\mathbf{n}=39)\end{array}$ & $\begin{array}{c}\text { Non anemic women } \\
(\mathbf{n}=35)\end{array}$ & p \\
\hline SOD (UI/L) & $879.6 \pm 689.5$ & $1056.4 \pm 762.1$ & $682.6 \pm 543.9$ & $<0.02$ \\
Oxidized LDL (UI/L) & $322.9 \pm 216.5$ & $439.6 \pm 209.5$ & $192.8 \pm 136.3$ & $<0.001$ \\
Uric acid (mg/L) & $2.8 \pm 1.01$ & $2.6 \pm 1.03$ & $3.03 \pm 0.9$ & 0.088 \\
Fasting glycemia (g/L) & $74.4 \pm 15.8$ & $75.3 \pm 15.9$ & $73.4 \pm 15.9$ & 0.614 \\
\hline
\end{tabular}


UI/L; P < 0.001). No significant differences were found for uric acid and glycemia.

Our study did not find any correlation between the level of hemoglobin and markers of iron and oxidative status ( $\mathrm{p}$ not significant), except for ferritin ( $\mathrm{r}=$ 0.5 ; slope $y=63.67+8.25 * X ; P<0.05)$.

Grouping oxidative stressed women according to thresholds of oxidative markers (Table 4.) showed that $81.1 \%, 0 \%, 55.4 \%$ and $2.7 \%$ of women were positive for SOD, uric acid, oxidized LDL and glycemia, respectively. So, uric acid and glycemia failed to recognize oxidative stressed subjects. The same calculations concerning markers of oxidation sources showed proportions of stressed women of $54.1 \%, 79.7 \%$ and $100 \%$ for ferritin, serum iron and transferrin saturation, respectively, meaning that serum iron and ferritin approached discrimination values found for SOD and oxidized LDL. Transferrin did not exclude any women from being oxidative stressed.

\section{Discussion}

There has been an increasing claim of deleterious effects of routine iron supplementation during pregnancy, mostly among women with relative high hemoglobin values [4] [5]. However, no study from developing countries has focused on related oxidative stress likely to derive from excess iron. This is expected to occur when supplementation is initiated irrespective of initial iron status of women concerned. Our study was carried out to assess baseline iron and oxidadive status in a group of pregnant women in order to better appreciate those in actual

Table 4. Recognition of oxidative stress according to different markers.

\begin{tabular}{cccc}
\hline & & $\mathbf{n}=\mathbf{7 4}$ & $\%$ \\
\hline SOD (UI/L) & Normal (785 - 1570) & 14 & 18.9 \\
& Pathologic & 60 & 81.1 \\
Uric acid (mg/L) & Normal (22 - 60) & 74 & 100 \\
& Pathologic & 0 & 0 \\
Oxidized LDL (UI/L) & & & \\
& Normal (200 - 600) & 33 & 44.6 \\
& Pathologic & 41 & 55.4 \\
Serum iron ( $\mu$ g/dl) & Normal & 15 & 20.3 \\
& Pathologic & 59 & 79.7 \\
Ferritin (ng/ml) & Normal & 34 & 45.9 \\
& Pathologic & 40 & 54.1 \\
& Normal (0.60 - 1.10) & 72 & 97.3 \\
& Pathologic & 2 & 2.7 \\
\hline & & &
\end{tabular}


need of iron supplementation.

The rate of anemic pregnant women found in our study (52.2\%) has been quite constant in our setting for years [2], meaning endemicity of anemia among pregnant women in our country. This high rate is common in deprived areas [1] [8] [18], although lower rates have been observed in Tanzania (47\%) [9] and in Ethiopia (31.7\%) [10]. Our results also show higher proportion of intestinal parasitosis and lower iron intake among anemic women, both to be considered causative of anemia along with malaria (not addressed in our protocol). Low socioeconomic conditions are to be pointed out as well due to inappropriate nutritional intake along with bad hygienic conditions that favour hookworms infestation. This corroborates other studies carried out in similar environments [11] [13] [14] [15] [16] [17] [19]. This situation will thus change only if poverty is reduced and is supportive of routine iron supplementation during pregnancy as well as other preventive measures.

Such a poor hemoglobin profile is expectedly reflected in low body/blood markers of iron status that in turn might be associated with high risk of oxidative stress. Indeed, some of markers of iron status (namely serum iron and ferritin) are also markers of oxidative stress. Values observed in our overall study group for iron $(73.3 \pm 45.7 \mu \mathrm{g} / \mathrm{dl})$ and ferritin $(20.9 \pm 18.6 \mathrm{ng} / \mathrm{ml})$ are comparable with those reported at similar gestational age in Morrocco $(69.4 \pm 4 \mu \mathrm{g} / \mathrm{dl}$ and $17 \pm 1.6 \mathrm{ng} / \mathrm{ml}$, respectively) [6], Irak $(51.97 \pm 14.20 \mu \mathrm{g} / \mathrm{dl}$ and $14.69 \pm 5.9$ $\mathrm{ng} / \mathrm{ml}$, respectively) [20] and India (mean serum ferritin of $60.42 \pm 20.24-47.33$ $\pm 13.49 \mathrm{ng} / \mathrm{ml}$ ) [21], but lower than values from wealthy environments (26 - 38 $\mathrm{ng} / \mathrm{ml}$ for ferritin) [22]. Ferritin reflects iron storage in the body, and it is claimed that in the absence of inflammatory situation the lowest levels are close to $15 \mathrm{ng} / \mathrm{ml}$ [23]. So, the level of our overall group $(20.9 \pm 18.6 \mathrm{ng} / \mathrm{ml})$ as well as that of the anemic subgroup $(7.5 \pm 3.9 \mathrm{ng} / \mathrm{ml})$ at \pm 16 weeks of gestation is very low since it is expected to decrease over pregnancy. In Abidjan, Côte d'Ivoire, Bléyéré [8] reported that $65 \%$ of pregnant women had $6.2-20 \mathrm{ng} / \mathrm{ml}$ of ferritin at the second trimester, indicating a quite similar profile.

As of the oxidative status, our study showing significantly higher level of oxidants (oxidized LDL) in anemic women gives consistency to the fact that maternal anemia may count a lot into oxidative stress likely to be found in these women. This is in accordance with most of studies showing rise of oxidative stress associated with anemia [4] [5] [6] [24] [25] [26] [27]. In an Indian series [26], however, It was seen that women who started their pregnancy with a high $\mathrm{Hb}$ actually had a higher level of oxidative stress as evidenced by higher levels of lipid peroxides and lower activity of paraoxonase-1 (one of the key enzymes that protects LDL from oxidation). During pregnancy SOD activity is expected to decrease, in relation with oxidative environment [4] [5] [6].

Combining assessment of both oxidants and anti-oxidants helps get balance that could better explain pregnancy outcomes. Oxidative stress might exist only if antioxidant capacity fails to oppose oxidative activity [4] [5] [6] [25] [27]. It 
could thus be expected that increased levels of oxidants are allied with decreased antioxidants, a tendency not found in our series reporting higher levels of both oxidants and antioxidants in anemic women. Rise in SOD as found in our study seems conflicting but might be suggestive of increasing need to fight insult of oxidative stress as pregnancy proceeds. Indeed, SOD faces oxidative stress in two ways: first, when the insult is still moderate there is a superexpression of SOD; if the situation does not resolve a massive production of toxic reactive oxygen species will occur so that SOD will be destroyed, which will result in decrease of its concentration [27]. This illustrates difficulties to accurately assess the true oxidative stress status of the organism as it has been pointed out by some authors also reporting conflicting results in anemic patients [25]. This can be (at least in part) owed to the fact that deficiencies of non-enzymatic antioxidants (e.g. vitamin C, vitamin E) are rarely taken in account.

Due to technical and financial constraints we restricted measurement of antioxidant capacity in our study to SOD (the main antioxidant) and uric acid, while that of oxidants was based on oxidized LDL (the main unsaturated lipid from which lipid peroxides are formed), this latter being the standard marker of oxidative stress. Blood glucose and other biological oxidants (free iron, ferritin) that also reflect body iron status were to be considered as well.

Our results (Table 4) are consistent with use of serum iron, ferritin, SOD and oxidized LDL as markers of oxidative status in our setting. However, correlations between the level of hemoglobin and these markers of oxidative stress that has been reported in some series [5] were not found in our study (except for ferritin).This could be owed to factors not assessed by us. Variations of parameters of the study are likely to occur over pregnancy, due to increased hemodilution and maternal/fetal demand.

Using a perceived stress score to measure psychosocial stress among pregnant women in Kinshasa [28], we found that average 57\% qualified as stressed. Such a rate is in the range of pathologic value $(54 \%-81 \%)$ displayed by markers of stress in our study (Table 4). This is to emphazise the additional role of anemic situation in generation of oxidative stress in Africa where the question of stress in general and oxidative stress in particular still seems not to matter. This limits the possibilities of comparison with other African settings.

Our study is one of the first to question and establish a potential link between maternal anemia and oxidative stress in sub-Saharan area. This is basis for actual assessment of maternal/perinatal benefits of iron supplementation during pregnancy, mostly in conditions where a deficient iron absorption precedes pregnancy. Nevertheless, many other factors are to be taken in account beside baseline iron and oxidative status of pregnant women, such as enhancing or limiting factors of iron absorption.

The main limitation of this study is its small sample size, a situation common to studies dealing with markers of oxidative stress during pregnancy, even in developed settings. This is probably due to the cost of dosages such as in our 
study that has scheduled three samplings for each woman till confinement. This represents a serious burden for an own funded study.

\section{Conclusion}

The rate of anemic mothers found in our study (52.2\%) has been quite constant in our setting for years, meaning endemicity. Serum iron and ferritin were significantly lower in anemic women, which is supportive of routine iron supplementation during pregnancy. Significantly higher level of SOD and oxidized LDL in anemic women suggests that maternal anemia may count into oxidative stress in these women.

\section{Conflicts of Interest}

None.

\section{Author's Contributions}

MMA is the principal investigator, participated in designing the study and was actively involved in data collection and statistical calculations. TUB generated and designed the study. He drafted the first manuscript. MMR participated in designing the study and analyzing the results. All authors contributed in preparing the final manuscript.

\section{References}

[1] Di Renzo, G.C., Spano, F., Giardina, I., Brillo, E., Clerici, G. and Roura, L.C. (2015) Iron Deficiency Anemia in Pregnancy. Womens Health, 11, 891-900.

[2] Tandu-Umba, B. and Mbangama, M.A. (2015) Association of Maternal Anemia with other Risk Factors in Occurrence of Great Obstetrical Syndromes at University Clinics, Kinshasa, DR Congo. BMC Pregnancy and Childbirth, 15, 183. https://doi.org/10.1186/s12884-015-0623-Z

[3] Mbangama, M.A, Tandu-Umba, B. and Mbungu, M.R. (2018) Rationale of a Cohort Study on Risk of Obstetrical Outcomes Associated with Iron Supplementation during Pregnancy. Open Journal of Obstetrics and Gynecology, 8, 598-609. http://www.scirp.org/journal/ojog https://doi.org/10.4236/ojog.2018.86066

[4] Casanueva, E. and Viteri, F.E. (2003) Iron and Oxidative Stress in Pregnancy. Journal of Nutrition, 133, 1700S-1708S. https://doi.org/10.1093/jn/133.5.1700S

[5] Wisdom, S.J., Wilson, R., McKillop, J.H. and Walker, J.J. (1991) Antioxidant Systems in Normal Pregnancy and in Pregnancy-Induced Hypertension. American Journal of Obstetrics \& Gynecology, 165, 170-174. https://doi.org/10.1016/0002-9378(91)90018-M

[6] Zhuang, T., Han, H. and Yang, Z. (2014) Oxidative Stress and Gestational Diabetes. Nutrients, 6, 3968-3980. https://doi.org/10.3390/nu6093968

[7] Mpawenimana, S. (2010) Suivi de l'évolution du statut martial au cours de la grossesse: Etude prospective réalisée à l'Hôpital Militaire d'Instruction Mohamed V de Rabat.

[8] Bléyéré, N.M. (2010) Evaluation et caractérisation du statut martial chez les femmes 
en âge de procréer non enceintes et les femmes au cours de la grossesse en Côte d'Ivoire: Étude multicentrique dans la ville d'Abidjan. Université Nangui Abrogoua (ex université d'Abobo-Adjamé) - Doctorat unique d'Université.

[9] Msuya, S.E., Hussein, T.H., Uriyo, J., Sam, N.E. and Stray-Pedersen, B. (2011) Anaemia among Pregnant Women in Northern Tanzania: Prevalence, Risk Factors and Effect on Perinatal Outcomes. Tanzania Journal of Health Research, 13, 33-39. https://doi.org/10.4314/thrb.v13i1.60881

[10] Getachew M.K., Achenef A.M., Abadi K.B. and Gedefaw A.F. (2017) Prevalence and Determinants of Anemia among Pregnant Women in Ethiopia; a Systematic Review and Meta-Analysis. BMC Hematology, 17, 17. https://doi.org/10.1186/s12878-017-0090-z

[11] Ivoke, N., Eyo, E.J., Ivoke, N.O., Nwani, D.C., Odii, C.E., Asogw C.N., et al. (2013) Anaemia Prevalence and Associated Factors among Women Attending Antenatal Clinics in South Western Ebonyi State, Nigeria. International Journal of Medical Sciences, 46, 1354-135.

[12] Imene, B. (2013) Détermination du statut oxydant/antioxydant au cours de la grossesse obèse avec ou sans complications (Diabète, Hypertension) dans la région de Tlemcen. Mémoire en vue de l'obtention du diplôme de Master en Biologie Université Abou Bekr Belkaïd Tlemcen.

[13] Meseret, A., Bamlaku, E., Aschalew, G., Tigist, K., Mohammed, S., Yadessa, O., et al. (2013) Prevalence of Anemia and Associated Risk Factors among Pregnant Women Attending Antenatal Care from Gondar Town, Northwest Ethiopia. Journal of International Histology, 1, 137-144.

[14] Melku, M., Addis, Z., Alem, M. and Enawgaw, B. (2014) Prevalence and Predictors of Maternal Anemia during Pregnancy in Northwest Ethiopia. Hindawi Publishing Corporation, Article ID: 108593.

[15] Ouedraogo, S., Koura, K.G., Accrombessi, K.M., Bodeau-Livinec, F., Mssougbodji, A., Cot, M., et al. (2012) Maternal Anemia at First Antenatal Visit: Prevalence and Risk Factors in a Malaria-Endemic Area in Benin. American Journal of Tropical Medicine \& Hygiene, 87, 418-424. https://doi.org/10.4269/ajtmh.2012.11-0706

[16] Horque, M., Horque, E. and Kader, S.B. (2009) Risk Factors of Anaemia in Pregnancy in Rural Kwazulu-Natal South Africa, Implication for Health Education and Promotion. South African Family Practice, 51, 68-72.

[17] Tefera, G. (2014) Determinants of Anemia in Pregnant Women with Emphasis on Intestinal Helminthic Infection at Sher-Ethiopia Hospital, Ziway, Southern Ethiopia. Immunology and Infectious Diseases, 2, 33-39.

[18] Black, R.E., Victora, C.G., Walker, S.P., Bhutta, Z.A., Christian, P., De Onis, M., et al. (2013) Maternal and Child Undernutrition and Overweight in Low-Income and Middle-Income Countries. The Lancet, 382, 427-451. https://doi.org/10.1016/S0140-6736(13)60937-X

[19] Bisoi, S., Haldar, D., Majumdar, T.K., Bhattacharya, N., Sarkar, G.N., Ray, S.K., et al. (2011) Correlates of Anemia among Pregnant Women in a Rural Area of West Bengal. Journal of Family Welfare, 57, 72-78.

[20] Talabani, N.S. (2015) Monitoring Levels of Iron, TIBC, Hb, Transferrin and Ferritin during Pregnancy Trimesters and Lactation in Sulaimania City/Iraq. International Journal of Medical and Health Research, 1, 23-25. http://www.medicalsjournals.com

[21] Kumar, S., Dubey, N. and Khare, R. (2017) Study of Serum Transferrin and Serum Ferritin during Pregnancy and Their Correlation with Pregnancy Outcome. International Journal of Medical Sciences and Public Health, 6, 118-122. 
https://doi.org/10.5455/ijmsph.2017.04072016570

[22] Milman, N., Taylor, C.L., Merkel, J. and Brannon, P.M. (2017) Iron Status in Pregnant Women and Women of Reproductive in Europe. American Journal of Clinical Nutrition, 106, 1655S-1662S. https://doi.org/10.3945/ajcn.117.156000

[23] Friedrisch, J.R. and Friedrisch, B.K. (2017) Prophylactic Iron Supplementation in Pregnancy: A Controversial Issue. Biochemistry Insight, 10, 1-8. https://doi.org/10.1177/1178626417737738

[24] Ramachandran, M. and Iyer, G.Y. (1984) Erythrocyte Membrane Lipid Peroxidation in Iron Deficiency Anemia. Experientia, 40, 173-174. https://doi.org/10.1007/BF01963584

[25] Kurtoglu, E., Ugur, A., Baltaci, A.K. and Undar, L. (2003) Effect of Iron Supplementation on Oxidative Stress and Antioxidant Status in Iron Deficiency Anemia. Biology of Trace Elements Research, 96, 117-123. https://doi.org/10.1385/BTER:96:1-3:117

[26] Shastri, L., Pammal, R.S., Mani, I., Thomas, T. and Kurpad, A.V. (2016) Oxidative Stress during Early Pregnancy and Birth Outcomes. Public Health Nutrition, 19, 3210-3215. https://doi.org/10.1017/S1368980016001191

[27] Aslan, M., Horoz, M. and Çelik, H. (2011) Evaluation of Oxidative Status in Iron Deficiency Anemia through Total Antioxidant Capacity Measured Using an Automated Method. Turkisch Journal of Hematology, 28, 42-46.

https://doi.org/10.5152/tjh.2011.04

[28] Tandu-Umba, B., Dedetemo, K.D. and Mananga, L.G. (2014) Maternal Stress and Pregnancy Outcomes. Open Journal of Obstetrics and Gynecology, 4, 361-370. https://doi.org/10.4236/ojog.2014.47054 